and no previous reports of AEF in a patient with both a rightsided aortic arch and Kommerell diverticulum. Kommerell diverticulum (Figure 2) is a saccular aneurysmal dilation at the origin of an aberrant right or left subclavian artery. It is a rare anomaly that occurs in association with a double or left aortic arch and an aberrant right subclavian artery $(0.5 \%$ of the population) or with a right aortic arch and an aberrant left subclavian artery $(0.1 \%)$. Embryologically, it represents the persistent distal end of the interrupted fourth aortic arch, between the carotid and subclavian arteries. ${ }^{4}$ The question arises as to whether this congenital anomaly increases the likelihood of development of an AEF in response to disease or disruption. Kommerell diverticulum represents a likely area of weakening in the aortic wall that can also compress the esophagus and, in theory, could cause erosion of the structure into each other, especially when disruption of adventitial layers has occurred, such as with trauma.
In summary, long-term survival can be achieved with early diagnosis and prompt surgical management of AEF. Because this condition presents in a catastrophic manner, younger and healthier patients are more likely to have better outcomes. In our case, the patient's young age and the relatively small size of his AEF, as well as prompt diagnosis and surgical treatment, proved the ultimate determinants of success and are why he remains alive to this day.

\section{References}

1. Dubreuil O. Observations sur la perforation de l'esopphage et de l'aorte thoracique par une portion d'os avale: avee de reflexions. J Univ Sci Med. 1818;9:357-63.

2. Rodriguez E, Park P, Cowan S, Weinstein M, Kaulback K, Friedberg JS, et al Complicated management of a traumatic aortoesophageal fistula in a patient with a right-sided aortic arch. J Trauma. 2004;56:691-3.

3. Hollander JE, Quick G. Aortoesophageal fistula: a comprehensive review of the literature. Am J Med. 1991;91:279-87.

4. Arciniegas E, Hakimi M, Hertzler JH, Farooki ZQ, Green EW. Surgical management of congenital vascular rings. J Thorac Cardiovasc Surg. 1979;77:721-7.

\title{
Recurrent sarcoma originating from the pulmonary artery 6 years after extensive thoracic resection
}

Christine Fegbeutel, MD, ${ }^{a}$ Martin Strüber, MD, ${ }^{a}$ Jan U. Becker, MD, ${ }^{b}$ Florian Länger, MD, ${ }^{\mathrm{b}}$ Nicolas Dickgreber, MD,

Axel Haverich, MD, ${ }^{a}$ and Stefan Fischer, MD, MSc, ${ }^{a}$ Hannover, Germany

Sarcoma originating from the pulmonary artery (PA) is a rare tumor. In 1923, Mandelstamm ${ }^{1}$ was the first to describe this disease in an autopsy. Since then, fewer than 200 cases overall have been reported. Because of its rarity and insidious growth characteristics, PA sarcoma is often mistaken for pulmonary embolism, leading to inappropriate therapy such as prolonged anticoagulation or thrombolysis. ${ }^{2}$

Prognosis is usually poor with a median survival of approximately 12 months with surgical resection of the tumor and 1.5 months without surgical resection of the tumor. Several reports have shown that chemotherapy and radiotherapy may lead to prolonged survival. Only a few cases of complete remission after radical surgical resection have been re-

\footnotetext{
From the Department of Cardiac, Thoracic, Transplant, and Vascular Surgery, ${ }^{\mathrm{a}}$ Department of Pathology, ${ }^{b}$ and Department of Respiratory Medicine, ${ }^{\mathrm{c}}$ Hannover Medical School, Hannover, Germany.

Received for publication Nov 21, 2007; accepted for publication Feb 5, 2008.

Address for reprints: Stefan Fischer, MD, MSc, Director, Hannover Thoracic Surgery and Lung Support Program Department of Cardiac, Thoracic, Transplant, and Vascular Surgery, Hannover Medical School, Carl-Neuberg-Strasse 1, 30625 Hannover, Germany (E-mail: fischer.stefan@mh-hannover.de).

J Thorac Cardiovasc Surg 2008;136:1093-5

$0022-5223 / \$ 34.00$

Copyright (c) 2008 by The American Association for Thoracic Surgery

doi:10.1016/j.jtcvs.2008.02.006
}

ported. The longest survival times reported are 3.5 years and 5.5 years. ${ }^{3,4}$

We report the case of a 48-year-old female patient with recurrent sarcoma of the main PA mimicking fulminant PA embolism 6 years after extensive resection of the primary tumor.

\section{CLINICAL SUMMARY}

A previously healthy 42-year-old patient developed progressive respiratory distress over a period of several weeks as the result of pleomorphic sarcoma of the mediastinum with infiltration of the left atrium, both pulmonary arteries, the superior vena cava, right main stem bronchus with total occlusion of the right upper lobe, and lung parenchymal infiltration. After initial chemotherapy, surgical resection was performed, including right pneumectomy, resection of the PA bifurcation, and partial resection of the left atrium. The left atrium was patched with pericardial tissue, and the PA was reestablished in an end-to-end technique.

Because of perioperative acute pulmonary embolism, oral anticoagulation was initiated. The patient recovered with 

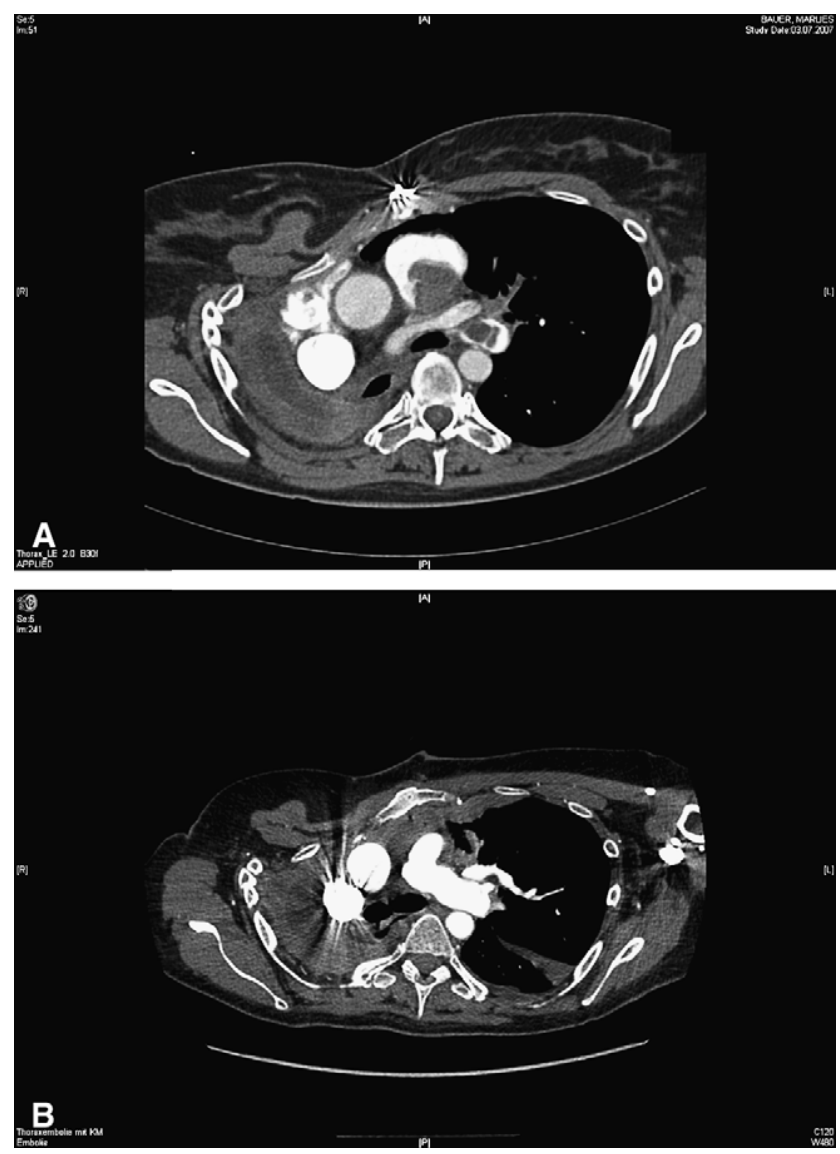

FIGURE 1. A, Transverse CT scan at the level of the left PA demonstrating an intraluminal filling defect almost causing an occlusion of the PA. B, Postoperative CT scan showing the homograft interposition reestablishing the PA.

mild to moderately reduced physical resilience and without the need for oxygen application.

Six years later, the patient presented with a sudden onset of dyspnea, cyanosis, and recurrent syncopal attacks. Despite oral anticoagulation with phenprocoumon, there was a large filling defect in the left PA, as depicted by computed tomography (CT) scan (Figure 1, $A$ ). Cardiac magnetic resonance imaging and magnetic resonance angiography of the chest showed no signs of tumor recurrence. There was no hypermetabolic activity observed by fluorodeoxyglucose positron emission tomography scan, and bronchoscopy findings were unremarkable. Echocardiography demonstrated moderate impairment of the right side of the heart with tricuspid regurgitation grade II and systolic PA pressure of $55 \mathrm{~mm} \mathrm{Hg}$. A presumptive diagnosis of pulmonary embolism was made, and thrombolysis was performed with 40 $\mathrm{mg}$ of recombinant tissue plasminogen activator. A followup CT scan of the chest failed to show any dissolution of the thrombus.

The patient was referred to the Hannover Medical School for further evaluation and pulmonary thromboembolectomy.
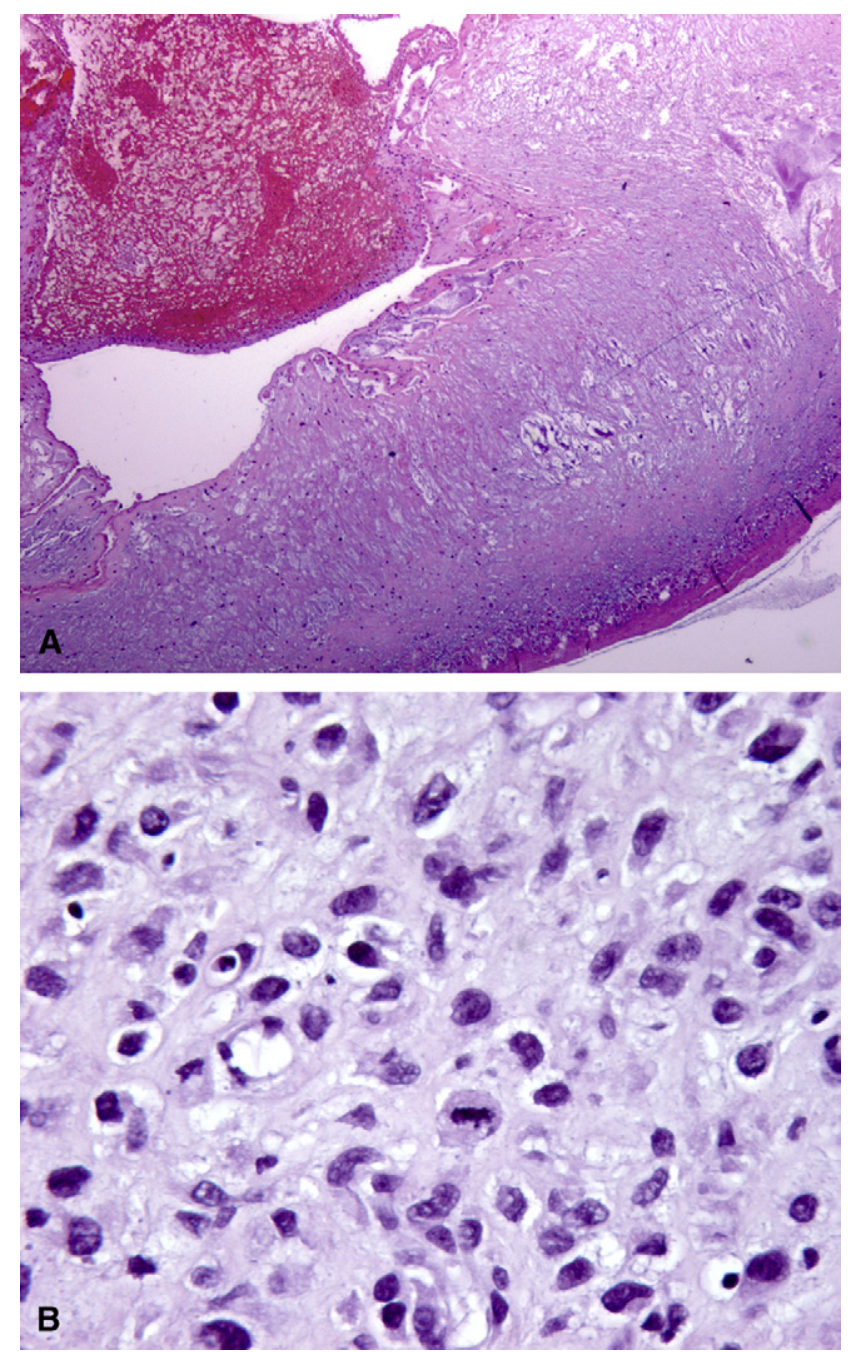

FIGURE 2. A, Intraoperative histology showing eosinophilic parts of a venous thrombus in the left corner and diffuse sarcomatous infiltration of the PA with myxoid, basophilic matrix (hematoxylin-eosin, magnification $\times 50$ ). B, Histology of the low-grade pleomorphic sarcoma with polymorphous nuclei and a mitotic figure. (hematoxylin-eosin, magnification $\times 400$.)

At that time, the patient was bedridden, oxygen dependent, and unable to perform minimal activity.

A redo median sternotomy was performed, and cardiopulmonary bypass was established through the ascending aorta and the right atrium (2-stage). In mild hypothermia, the main PA trunk was dissected and incised. A thrombus-like structure was found, which almost completely obstructed the PA extending from the commissural level of the pulmonary valve to the trifurcation of the first left upper lobe branch. An intraoperative frozen section revealed a thrombus with portions of sarcoma (Figure 2, $A$ and $B$ ). A supracommissural replacement of the PA main trunk using a PA homograft was performed, which was anastomosed with the left PA at the level of the first branch. The patient was weaned from bypass uneventfully and 
extubated within 6 hours after surgery. Her recovery was uneventful. She was discharged on postoperative day 7 with oral anticoagulation (international normalized ratio 2.5) and without oxygen substitution. A follow-up CT scan showed normal perfusion of the homograft (Figure 1, B). Eight months after the resection, the patient is recurrence-free.

\section{DISCUSSION}

The diagnosis of PA sarcoma is often not correctly established before surgery, ${ }^{4}$ as described in our case. Even though magnetic resonance imaging and positron emission tomography did not demonstrate any signs of malignancy, intraoperative and postoperative histologic examination showed relapse of the sarcoma. It is without doubt that even advanced and unique diagnostics, such as magnetic resonance imaging and positron emission tomography scanning once, again failed to distinguish pulmonary embolism from intravascular sarcoma. A definitive diagnosis of PA sarcoma requires the pathologic examination of tissue obtained by intravascular, percutaneous, or surgical biopsies. ${ }^{5}$
In this emergency situation, we were able to resect a sarcoma of the PA, which was mimicking fulminant acute pulmonary embolism with tumor-free resection margins, and to solve the acute problem. Improvements are required to establish the diagnosis of this disease correctly. Nevertheless, this case is rare and it shows the feasibility of resection of recurrent sarcomas in areas such as the great vessels even after extensive previous resection.

\section{References}

1. Mandelstamm M. Über primäre Neubildungen des Herzens. Virchows Arch Pathol Anat. 1923;245:43-54

2. Delany SG, Doyle TC, Bunton RW, Hung NA, Joblin LU, Taylor DR. Pulmonary artery sarcoma mimicking pulmonary embolism. Chest. 1993;103:1631-3.

3. Kramm T, Gaumann A, Heussel CP, Dahm M, Oelert H, Mayer E. [Surgica management of pulmonary artery sarcoma.] Dtsch Med Wochenschr. 2001;126: 1423-7.

4. Parish JM, Rosenow EC 3rd, Swensen SJ, Crotty TB. Pulmonary artery sarcoma: clinical features. Chest. 1996;110:1480-8.

5. Manso L, Alvarez E, Quintela M, Cortes-Funes H, Hitt R. Primary pulmonary artery sarcoma: report of three cases and review of the literature. Clin Lung Cancer. 2007;8:277-81.

\section{Mitral annuloplasty in an infant with Barth syndrome and severe mitral insufficiency: First case report and determination of annular diameter}

Shu-Chien Huang, MD, ${ }^{\mathrm{a}}$ En-Ting Wu, MD, ${ }^{\mathrm{b}}$ Shuenn-Nan Chiu, MD, ${ }^{\mathrm{b}}$ Wuh-Liang Hwu, MD, ${ }^{\mathrm{c}}$ Mei-Hwan Wu, MD, PhD, and Shoei-Shen Wang, MD, $\mathrm{PhD},{ }^{\mathrm{a}}$ Taipei, Taiwan

Barth syndrome, an X-linked recessive disorder, is caused by mutations in the taffazin gene (TAZ) at $\mathrm{Xq} 28$, leading to severe cardiolipin deficiency in the mitochondrial membrane. ${ }^{1}$ The most common presentation is cardiomyopathy in infancy, including left ventricular (LV) dilation, hypertrophy, and noncompaction, with congestive heart failure.

In the case of refractory heart failure, a heart transplant is considered to be required. ${ }^{2}$ We performed a successful mi-

\footnotetext{
From the Departments of Surgery, ${ }^{\mathrm{a}}$ Pediatrics, ${ }^{\mathrm{b}}$ and Genetics, ${ }^{\mathrm{c}}$ National Taiwan University Hospital, Taipei, Taiwan.

Received for publication Nov 25, 2007; accepted for publication Jan 17, 2008.

Address for reprints: Shoei-Shen Wang, MD, PhD, Department of Surgery, National Taiwan University Hospital, 7 Chung-Shan S Rd, Taipei 100, Taiwan (E-mail: sswang@ha.mc.ntu.edu.tw).

J Thorac Cardiovasc Surg 2008;136:1095-7

$0022-5223 / \$ 34.00$

Copyright (C) 2008 by The American Association for Thoracic Surgery

doi:10.1016/j.jtcvs.2008.01.031
}

tral valve repair on an infant with Barth syndrome with a presentation of cardiogenic shock. We describe the techniques and consideration for mitral valve repair for this infant.

\section{CLINICAL SUMMARY}

An 11-month-old boy had Barth syndrome, which had been diagnosed during his early infancy. Echocardiography revealed LV noncompaction with hypertrophy and impaired systolic function (LV ejection fraction 36\%) with severe mitral regurgitation (MR). He was treated with furosemide, captopril, and aspirin. He was also on the waiting list for a heart transplant.

The patient was admitted to the intensive care unit with the impression of cardiogenic shock. Echocardiography showed severe MR with dilated left atrium and LV (Figure 1, A). A short period of cardiac massage was required for profound shock and bradycardia; the cardiac surgeon was then 